\title{
The Effect Of Thematic Patterning Technique On Students' Writing Competency Of Tenth Grade Students At SMAN 4 Singaraja
}

\author{
Astiti, N. T. K. K ${ }^{1}$, Marhaeni, A.A.I.N ${ }^{2}$, Suputra, P.E.D ${ }^{3}$
}

${ }^{123}$ English Language Education, Ganesha University of Education, Bali, Indonesia

\section{A R T I C L E I N F O \\ Article history: \\ Received 20 March \\ 2020 \\ Received in revised \\ Form 01 August 2020 \\ Accepted 18 August \\ 2020 \\ Available online 30 \\ October 2020}

Keywords:

thematic patterning

\begin{abstract}
A B S T R A C T
This study aimed at investigating whether there is a significant effect of the implementation of Thematic Patterning Technique on students' writing competency of the tenth grade students at SMAN 4 Singaraja. This is an experimental research. The population of this study was the tenth grade students. There were two classes, consist of 75 students who were chosen as the samples of the study. Random sampling was used in order to find out the Experimental group and the Control group. This study was designed Posttest Only Non Equivalent Control Group design. The results of the posttest were analyzed descriptively and inferentially. Moreover, the results found that there was a significant difference of implementing thematic patterning technique on students' writing competency of tenth-grade students at SMAN 4 Singaraja since, the students who were taught by using thematic patterning technique got higher score than students who were taught by using conventional technique (inquiry).
\end{abstract}

\section{Introduction}

Writing is a media of communication that human use to share ideas, feeling, and information to others in written form. Writing is also a reflective activity which makes students recalling their background knowledge to transfer a message to the readers Saed \& AL-Omari, 2014). According to Indriyanti \& Prasetyo (2018) writing is known as an indirect communication in which it needs deep thinking process for a better understanding. It meant that deep thinking process was needed in writing so others can get the writer's intended message, ideas, or information even when they are not facing each other. The competency that students use to achieve particular language. Trough writing competency students were able to create a text based on their idea in their mind. In conclusion, this study defined writing competency as the level of understanding that students have achieved in regards to write their own piece of text. Many students still found it difficult to write a good piece of writing. Javed,et al. (2013) stated that writing has become one of the difficult skills to be learned because there are a lot of things that students should take more attention while they are writing. It was also supported as result of the pre-observation of this study at SMAN 4 Singaraja showed the students' problems in writing were: finding the right topic, developing idea, and the lack of vocabulary that lead students to be lacking of coherence. It was assumed the reason of these problems was the teacher's monotonous technique in teaching writing. Based on the problems mentioned above, the writer suggested Thematic Patterning technique which was proposed by Danes (1974) as an alternative technique to teach writing. According to Alonso, I., \& McCabe (2003), Thematic Patterning technique is a technique which helps students to write coherently. Thematic Patterning Technique offered three main types of patterns in order to guide students to organize the flow of information which was stated in every sentence in writing a text, namely linear pattern, constant pattern, and hypertheme pattern. Constant pattern refers to the pattern in which the first theme in a clause being repeated in other clauses, linear pattern refers to a pattern in which a theme repeats or transforms the rheme of the preceding clause while hypertheme pattern or derived pattern refers to a pattern in which the complex theme of a text presents other information that will be described into several sub-themes. This study purposed to investigate whether there was a significant difference in students' writing competency between the students who were treated by Thematic Patterning Technique and those who were treated by a conventional technique in SMAN 4 Singaraja. 
Moreover, this study focused on the use of Hypertheme pattern in writing descriptive text since the used of constant and linear pattern were more frequent than hypertheme pattern.

\section{Methods}

The research design used in this study was Experimental study using Post-test Only Non Equivalent Group Design. There were two groups in this study namely experimental group: a group which was taught by Thematic Patterning technique that was X MIPA 4, and control group; a group which was taught by conventional technique that was X MIPA 6. During the implementation, the researcher was helped by the teacher. Besides that, teacher was guided by the lesson plan, scoring rubric, and the blue print which was prepared before by the researcher.

\section{Result and Discussion}

In this study, the experimental group and the control group were treated by different technique. The experimental group, X MIPA 4 class, which was treated by Thematic Patterning technique. Meanwhile, the control group, X MIPA 6 class was treated by conventional technique in this case, inquiry technique. Moreover, before the treatment were given to control and experiment group, there was a test that was prepared by the researcher of this study. The test was given to the group which was not belonging to control and experimental group. The result of the test which was given to the group (that was not belonging to control and experiment group) was examined by the content validity, before it was given to the control and experiment group. Moreover in order to check the validity of the test, this study used Gregory formula. Thus, based on the result of Gregory formula, it was found that the content validity of the test was 1 that was classified as very high qualification. It meant that the test can be used as the posttest in this study in which it will be given to both of the groups after the treatments were done. This study used descriptive analysis and inferential analysis in order to measure the significant effect on students' writing competency of the tenth grade students at SMAN 4 Singaraja.

The result of Descriptive statistics in this study involved the information about the mean, median, mode, range, standard deviation and variance between the experimental and control classes' post-test result. The data were analysed by using SPSS 23 . Table 1 showed the result of the descriptive statistical analysis.

Table 1. The Result of Descriptive Statistical Analysis

\begin{tabular}{|c|c|c|c|c|c|}
\hline $\mathbf{N}$ & & $\begin{array}{c}\text { Experiment } \\
\text { Pre Test }\end{array}$ & $\begin{array}{l}\text { Experiment } \\
\text { Post Test }\end{array}$ & $\begin{array}{c}\text { Control Pre } \\
\text { Test }\end{array}$ & Control Post Test \\
\hline & Valid & 38 & 38 & 37 & 37 \\
\hline & Missing & 37 & 37 & 38 & 38 \\
\hline Mean & & 67,2632 & 79,1842 & 68,2432 & 74,8378 \\
\hline Median & & 66,0000 & 78,0000 & 68,0000 & 74,0000 \\
\hline Mode & & $61,00^{a}$ & 78,00 & 71,00 & 68,00 \\
\hline Std. Deviation & & 5,23339 & 6,69350 & 5,55480 & 5,70338 \\
\hline Variance & & 27,388 & 44,803 & 30,856 & 32,529 \\
\hline Range & & 20,00 & 24,00 & 17,00 & 21,00 \\
\hline Minimum & & 60,00 & 68,00 & 60,00 & 68,00 \\
\hline Maximum & & 80,00 & 92,00 & 77,00 & 89,00 \\
\hline Sum & & 2556,00 & 3009,00 & 2525,00 & 2769,00 \\
\hline
\end{tabular}

Based on Table 1 the mean score of the experimental group who were taught by Thematic Patterning technique was 79.18. However, the mean score of control group who were taught by using conventional technique was 74.84. Therefore, based on the Table above, the experimental group achieved higher mean score rather than the control group $(79.18>74.84)$. The median score of the experimental group was 78. Meanwhile, the median score for control group was 74 . Thus, it can be concluded that the median score of the control group was lower than the median score of the experimental group. The mode in experimental group was 78, while the mode score for the control group was 68 . The maximum score of 
experimental group was 92 and the lowest score was 68. It meant that the range score of the experimental group was 24 . On the other hand, the maximum score of control group was 89 , and the lowest score in this group was 68. It showed that the range of the control group was 21 . The standard deviation of experimental group was 6.693 while the standard deviation of the control group was 5.703. The variance of experimental group was 45.80 and the variance of the control group was 32,53.

Inferential statistics was done in order to measure whether or not there was significant difference between the students who were treated by Thematic Patterning and those who were treated by conventional technique towards students' writing competency of tenth-grade students at SMAN 4 Singaraja. Before the data were analysed inferentially by using independent sample t-test, the data should be normal and homogenous. In this study, the data were measured by using SPSS 23 program. The result of normality test of post-test can be seen in table 2 :

Table 2. Normality Test of Post-test

\begin{tabular}{lccc}
\hline Class & \multicolumn{3}{c}{ Kolmogorov-Smirnov $^{\mathbf{a}}$} \\
& Statistic & df & Sig. \\
\hline Post Test Experiment &, 097 & 38 & \multirow{2}{*}{, $200^{*}$} \\
Class &, 123 & 37 &, 171 \\
Control Class & & & \\
\hline
\end{tabular}

Based on the result of the normality test of Kolmogorov Smirnov above, it was found that the significant value (.Sig) of each group had exceeded the value of 0.05 . On the table above, it showed that the significance value of tests of normality reached by the experimental group was 0.200 and the significance value reached by the control group was 0.171 . Therefore, it can be concluded that the data obtained in this research were normally distribute.

After the normality test done, homogeneity test was conducted. This study used Levene' statistics in order to test the homogeneity of the data in both groups. Groups were considered as homogeneous if the significance value of the obtained data exceeds 0.05 . The result of the homogeneity test of the post-test of both groups can be seen as in table 3 :

Table 3. Homogeneity of Variances of Post test

\begin{tabular}{|c|c|c|c|c|}
\hline & Levene Statistic & df1 & df2 & Sig. \\
\hline Post Test & ,734 & 1 & 73 & 394 \\
\hline
\end{tabular}

Based on Table above the Levene Statistic significance value (Sig.) was 0.394 . The significance value was higher than 0.05 . It means that the data were homogeneous.

From the Kolmogorov Smirnov and Levene statistic test, it was found that the data of both sample groups had a normal distribution and homogeneous data variance. After that, the independent sample t-test as the mean of hypothesis testing was conducted. The independent sample t-test was used to find out if there is a significant difference of using thematic patterning technique towards students' writing competency of tenth-grade students at SMAN 4 Singaraja. In this study, the independent-samples t-test was used since this study compared the means of two sample groups namely experimental group and control group.

The data was then analyzed by using independent-sample t-test. Table 4 showed the result of independent sample t-test:

Table 4. The Result of Independent Samples T-Test

\begin{tabular}{cccccc}
\multicolumn{2}{c}{$\begin{array}{c}\text { Levene's Test for Equality of } \\
\text { Variances }\end{array}$} & \multicolumn{3}{c}{ t-test for Equality of Means } \\
\hline F & Sig. & T & Df & $\begin{array}{c}\text { Sig. (2- } \\
\text { tailed) }\end{array}$ \\
\hline
\end{tabular}




\begin{tabular}{|c|c|c|c|c|c|c|}
\hline \multirow[t]{2}{*}{$\begin{array}{l}\text { Post } \\
\text { Test }\end{array}$} & $\begin{array}{l}\text { Equal variances } \\
\text { assumed }\end{array}$ & \multirow[t]{2}{*}{ 734 } & \multirow[t]{2}{*}{,394 } & 3,023 & 73 & ,003 \\
\hline & $\begin{array}{l}\text { Equal variances not } \\
\text { assumed }\end{array}$ & & & 3,030 & 71,750 & 003 \\
\hline
\end{tabular}

There were two rows of data in the above are "Post test Equal variances assumed" and "Post test Equal variances not assumed". The first set of statistics which was "Levene's Test for Equality of Variances" was analyzed. The results above showed that the significant value (sig.) of the Levene's Test was 0.394 . It meant that the sig. value was higher that the value of 0.05 (the standard alpha level). In other words, it can be said that the sample groups were considered as homogenous in data variances. It was because there was no significant difference in the variance, therefore the row "Equal variances assumed" should be read in order to interpret this result. Next, observing the observed level of significance (Sig. 2tailed $)=0.003$ which means it was lower than the standard alpha level $(\alpha=0.05)$. Therefore, based on the criteria of determining a significance difference, the difference in the mean score of the samples was significant and null hypothesis (Ho) was rejected. Therefore, in relation with the statistical analysis, there was a significant difference on students' writing competency of the tenth-grade students who were taught by using Thematic Patterning technique at SMAN 4 Singaraja. The effect size of this study was measured using Cohen's d formula. The Effect size can be formulated as below:

$$
\begin{gathered}
d=\frac{M_{\text {group } 1}-M_{\text {group } 2}}{S D_{\text {pooled }}} \\
d=\frac{M_{\text {group } 1}-M_{\text {group } 2}}{\sqrt{\left(S D_{\text {group } 1}^{2}+S D_{\text {group } 2}^{2}\right) / 2}} \\
d=\frac{79-75}{\sqrt{\left(7^{2}+6^{2}\right) / 2}} \\
d=\frac{4}{6,51} \\
d=0,614
\end{gathered}
$$

Based on data above, it showed that the result of effect size was 0.61. According to Cohen (as cited in Lakens, 2013) showed 0.61 was categorized as having medium effect size. The standard of Cohen's d effect size can be seen on table 5 :

Table 5. Cohen's d effect size Interpretation

\begin{tabular}{ll}
\hline Value & Interpretation \\
\hline $0.20 \geq \mathrm{d} \leq 0.50$ & Small Effect Size \\
$0.50 \geq \mathrm{d} \leq 0.80$ & Medium Effect Size \\
$\mathrm{d} \geq 0.80$ & Large Effect Size \\
\hline
\end{tabular}

This study aimed to investigate the significant difference of implementing thematic patterning technique on students' writing competency for tenth grade students at SMAN 4 Singaraja. In order to do this research, the researcher recruited the samples. There were two samples that were used in this study; 
X MIPA 4 class and X MIPA 6 class of SMPN 4 Singaraja. both of the classes were chosen randomly by using random sampling. As the result, it was found that X MIPA 4 was selected as the experimental class. Meanwhile, X MIPA 6 was selected as the control class. Students in experimental class were taught by using thematic patterning technique. On the other hand, students in control class were taught by using conventional technique.

In order to implement the technique, the researcher prepared lesson plans for both of the group. This lesson plan was used as guidance for the researcher in implementing the technique. There were six lesson plans used in this study for each of the classes. It meant that, there were six meeting for both of the classes. Experimental class and the control class were taught about descriptive text. The students were asked to write a descriptive text about historical building place and tourism destination. After all the treatments were done by experimental class and the control class, both of them were given a posttest. This study used descriptive analysis and inferential analysis in order to analyse the data of the posttest.

In descriptive statistical analysis showed that the score of experimental class was higher than the control class. From the previous data, it was found that the mean score of experimental class was 79.18. Meanwhile, the mean score of the control class was 74, 84. In this study, the range of the experimental class was 24 . However, the range of the control class was 21 . Those result showed that, the range of the experimental class was higher than the range of control class. Based on the result which already described above, it can be concluded that students in experimental class who were taught by thematic patterning technique reached a better score rather than the students' in control class who were taught by conventional technique.

After the data of posttest was calculated by descriptive statistics, then the data was calculated by using inferential statistic. This study used independent sample t-test. Based on the result of independent sample t-test, it showed that there was a significant different from the use of thematic patterning technique through students' writing competency between experimental class and control class. Due to the result of the observed level of significance (Sig. 2-tailed) $=0.003$ which was lower than the standard of alpha level $(\alpha=0.05)$. Therefore, based on the criteria of determining a significance difference, the difference in the mean score of the samples is significant and null hypothesis (Ho) was rejected. This accepted the alternative hypothesis in which stated that there is a significant difference on students' writing competency of tenth grade students at SMAN 4 Singaraja.

Furthermore, based on the result of effect size, it was found that the effect of implementing thematic patterning technique on students' writing competency gave medium effect. It was because the result showed that the effect size of the data was 0.61 . According to Cohen as cited in Lakens (2013), 0.61 was categorized as medium effect. It also meant that thematic patterning technique gave good effect towards students' writing competency. However, even the Thematic Patterning technique already implemented by several researchers, but it still does not give big effect on students' writing competency. It is because there are some problem faced by the teacher during the implementation of this technique. Some students are too noisy during the learning process, because they are really interest in answering teacher's question. Besides that, a big number of students make teacher harder to control the students one by one. This make some students not in control and lead them to talk with their friend. In the first time of implementing Thematic Patterning technique, teacher found difficulties in introducing the theme and the rheme. It is because students do not really know and understand about the theme and the rheme. Therefore, teacher gives several questions which make students can understand the theme and the rheme. The last was the time allotment. In implementing thematic patterning technique to teach students writing competency, the time which was 90 minutes sometimes was not enough to complete a meeting since students should know the complex theme and the sub-themes first. Besides that students also should know the way how to develop the sub theme of each paragraph. Therefore, teacher needed more time in explaining it.

In relation with the other study, this study showed the same result with the other previous study which was done by some researcher. It can be seen since students' writing competency especially in five main aspects in writing was increased. The five main aspects was content, organization, sentence structure, vocabulary, and mechanism. In content, it was found that students were guided to choose the main idea and also supporting details easily. It was because the students were guided to decide the theme first and then they develop the idea through deciding the rheme. who stated that students were indicated has clearly "planned" their method of development in their texts while they were writing by using hypertheme pattern. However, in organization, this study found that since students were taught by using thematic patterning technique, students were able to create flow information. also found that Thematic Patterning technique led students to develop the connection between clauses through the use of theme and rheme. In conclusion, thematic patterning technique led students to write well connected ideas. The next was sentence structure. . In reality, it was found that; before the teacher implemented Thematic 
patterning technique, students did not know whether or not they apply appropriate grammar, effective sentences, word order, and so on. It was because when teacher asked students to write a text, some students only copy paste a text in the internet which made them ignore the use of grammar, effective sentence, word order, and so on. However after teacher implemented thematic patterning technique, students looked so aware with their mistakes, and they were trying not to repeat the mistake again. Vocabulary was became the fourth aspect of writing. In this case, students' vocabulary was increased. It was because teacher used to tell students to find the meaning of the difficult words in the dictionary. also found that students can develop the next clause or complex clauses by inserting the difficult words that they found and deciding the effectiveness of that word to be used in the sentence with the chosen theme and rheme. The last was mechanism. Mechanism in this study refers to a written text which was free from misspelling, and words were capitalized correctly, and it was written neatly. In this aspect, the students' work becomes written neatly. It proved since students planned the theme and rheme before writing a text. found that the use of theme and thematic led students to write clauses in the logical connection. It made students' work become neatly.

In implementing the technique, teacher also played a game to make students more enjoy during the learning process. The game was a puzzle game in which students should answer the question from the teacher in order to see a piece of the puzzles. If students were right in answering the teacher's question, so they were allowed to guess what the puzzle is (the name of place). And for student, who can guess the picture, was given a chance to make description about the place. Finally if she or he can answer it correctly, she or he got bonus points given by the teacher. This bonus point made students became more interested in learning English especially learn how to describe a place.

As a result of this study, it proved that the implementation of thematic patterning technique was successful in giving a significant difference on the score of students' writing competency of tenth grade students at SMAN 4 Singaraja. It was proved since the result of descriptive analysis and the inferential statistic analysis showed that students in experimental class who were taught by thematic patterning technique, have a better achievement than students in the control class who were taught by conventional technique. All of the data which already calculated by descriptive analysis and inferential analysis proved that experimental class got higher score rather than the control class. Therefore, it can be concluded that the alternative hypothesis "Ha" that was "there is a significant difference on students writing competency between students who were taught by thematic patterning technique and those who were taught by conventional technique of tenth-grade students at SMAN 4 Singaraja." was accepted.

\section{Conclusion}

This study aimed to investigate the significant difference of implementing thematic patterning technique on students' writing competency for tenth grade students at SMAN 4 Singaraja. In order to do this research, the researcher recruited the sample. Moreover, there were two samples that were used in this study. The samples in this study were X MIPA 4 class and X MIPA 6 class. After that, both of the classes were chosen randomly by using random sampling. As the result, it was found that X MIPA 4 was selected as the experimental class. Meanwhile, X MIPA 6 was selected as the control class. In this study students in experimental class were taught by using thematic patterning technique. On the other hand, students in control class were taught by using conventional technique. In order to implement the technique, the researcher prepared lesson plans for both of the group. This lesson plan was used as guidance for the researcher in implementing the technique. There were six lesson plans used in this study for each of the classes. It meant that, there were six meeting for both of the classes.

This study concludes that there was a significant difference of implementing thematic patterning technique on students' writing competency of tenth-grade students at SMAN 4 Singaraja. In this case, the students who were taught by using thematic patterning technique got higher score than students who were taught by using conventional technique (inquiry). It proved from the calculation of two statistical analysis namely descriptive and inferential statistical analysis. In conclusion, the alternative hypothesis was accepted with medium effect of using thematic patterning technique to teach students' writing competency. Based on the finding, the researcher also provides three suggestions that can be explained as follow: 1) For the English teacher, it is suggested to implement thematic patterning technique while teaching students' writing competency since it can help students in giving guidance while they are writing. 2) Students are suggested to implement this technique independently in order to be able to write flow information through the theme and rheme.3) It is also suggested that this study could become a reference for other researcher who were interested in same topic. Besides that, other researchers could also conduct the same topic with different design, sample and period of study as well. 


\section{References}

Alonso, I., \& McCabe, A. (2003). Improving Text Flow in ESL Learner Compositions. The Internet TSEL Journal, 11(2).

Danes, F. (1974). Papers on Functional Sentence Perspective. Paris: House of the Czechoslovak Academy of Sciences.

Indriyanti, R., \& Prasetyo, Z. (2018). Improving the Experiment Report Writing Skills of Fifth Graders Through the Discovery Learning Method. Jurnal Prima Edukasia, Vol.06, No.01, pp.102-110, doi: https://dx.doi.org/10.21831/jpe.v6i1.17284.

Javed, M., Juan, W., \& Nazli, S. (2013). A Study of Students' Assessment in Writing Skill of the English Language. International Journal of Instruction, Vol. 6, No. 2, pp. 1694-609X.

Lakens, D. (2013). Calculating and reporting effect sizes to facilitate cumulative science : a practical primer for $\mathrm{t}$-tests and ANOVAs. Frontiers in Psychology, 4(11), 1-12. https://doi.org/10.3389/fpsyg.2013.00863

Saed, H., \& AL-Omari, H. (2014). The Effectiveness of a Proposed Program Based on a Mind Mapping Strategy in Developing the Writing Achievement of Eleventh Grade EFL Students in Jordan and Their Attitudes Towards Writing. Journal of Education and Practice, Vol.5, No.18, pp.88-109. 